\title{
Editorial
}

\section{Coronary artery disease and diabetes}

Patients with diabetes form a substantial proportion of patients with coronary artery disease. ${ }^{1}$ In some respects, the assessment, management, and outcome of these patients is different from patients without diabetes. This article outlines these differences in patients with symptomatic coronary disease and then focuses on the problems of managing high risk asymptomatic patients with diabetes. Should we and can we reliably identify these patients? Once identified, are they likely to benefit from intervention?

Diabetes is a strong and independent risk factor for the presence of coronary disease increasing the risk, particularly in women, between twofold and fourfold. ${ }^{2}$ In patients with diabetes, coronary disease is more extensive and severe, and cardiovascular death is three times more common than in non-diabetic patients. ${ }^{3}$ In patients with non-insulin dependent diabetes, a proportion of the increased risk can be explained by an excess and clustering of established cardiovascular risk factors. The mechanisms accounting for the remaining risk are poorly understood and relate in part to the consequences of hyperglycaemia and abnormalities of the coagulation and fibrinolytic systems.

In the settings of acute myocardial infarction and the secondary prevention of coronary disease, the relative benefits of medical treatment have been shown to be similar in patients with and without diabetes. In patients with diabetes and acute myocardial infarction, those with suboptimal blood glucose control have been shown to benefit substantially from insulin treatment. ${ }^{4}$

In patients with diabetes, most studies of coronary artery surgery have shown that the risks of death, myocardial infarction, and stroke are increased compared with nondiabetic patients. ${ }^{5}$ In those with diabetes and multivessel disease, the long term outcome after coronary angioplasty ${ }^{6}$ and saphenous vein grafting alone are particularly disappointing compared with the very favourable outcome of diabetic patients after re-vascularisation using internal mammary artery grafting. ${ }^{7}$ Disappointing results from some forms of revascularisation may deter referral of patients with diabetes for surgery and we need more information to help identify those who are likely to benefit from surgical rather than medical treatment. This is especially important as both have changed so much since the initial outcome studies. Future studies are planned that will enrol patients with diabetes and coronary artery disease, which would not automatically be surgically treated, and randomise them to either surgical or medical therapy. Most importantly, the patients will also be randomised to aggressive or standard blood glucose control. It will also be important to determine whether high risk patients with diabetes associated problems such as nephropathy are more appropriately treated with surgery. Until the results of these trials are available the indications for surgical treatment of patients with diabetes will continue to be similar to those for the general population and be based on symptom severity (which may be less reliable in patients with diabetes ${ }^{8}$ ), assessments of coronary anatomy, left ventricular function, and traditional surgical risk factors.

\section{Primary prevention}

There have been no primary prevention studies of coronary disease specifically in patients with diabetes. Although diet, weight loss, exercise, smoking cessation, and aggressive cor- rection of cardiovascular risk factors are likely to have important beneficial effects, ${ }^{910}$ clinicians are forced to extrapolate from the results of studies in non-diabetic patients. There are however important differences between the two populations, the most obvious being the management of hyperglycaemia. Clear evidence of the benefits of improved glycaemic control on cardiovascular outcome is not yet available but valuable information is expected from the United Kingdom prospective diabetes study later this year. ${ }^{11}$ In general, asymptomatic patients with diabetes are at increased risk of future coronary events and are likely to benefit more from primary prevention strategies. This effect can occur to such an extent that the distinction between primary and secondary prevention becomes somewhat blurred. A good example of this is primary prevention with statin therapy. Many asymptomatic patients with diabetes will have a predicted annual cardiac event rate in excess of $4.5 \%$ per year. At this level of risk the benefits of primary prevention with statin treatment are likely to be similar to those seen in the $4 \mathrm{~S}$ study (one cardiac event prevented per 13 patients treated for five years). ${ }^{12}$ The level of risk at which statin treatment should be initiated is the subject of much debate and has important practical and financial implications. Statin treatment has been shown to improve outcome when the annual event rate for the population is $1.5 \%$ per year. ${ }^{13}$ This is an unrealistic level of risk at which to intervene in the general population, but in view of the worse outcome after myocardial infarction and coronary surgery, it could be argued to be an appropriate threshold for intervention in patients with diabetes.

In patients with diabetes, the benefits of aspirin in primary prevention are likely to outweigh the risks when the annual cardiac event rate for untreated patients is $2.5 \%{ }^{14}$ and it is possible that the risk threshold for benefit is even lower. Risk thresholds for treatment with antihypertensive agents and oestrogen replacement have not been determined in patients with diabetes.

An assessment of absolute cardiac risk is now an accepted means of deciding whether to consider primary and secondary prevention strategies. Using data from studies such as Framingham, equations have been derived that estimate cardiac risk based on standard cardiovascular risk factors and the presence or absence of diabetes. ${ }^{15}$ In clinical practice they enable identification of a proportion of high risk asymptomatic patients but it is difficult to estimate the absolute risk for all patients with diabetes. Prospective epidemiological studies have too often failed to define adequately other factors that influence the probability of coronary disease such as the type of diabetes, the degree of blood glucose control, the presence of pre-existing vascular disease, and the presence of important diabetes complications such as nephropathy. More prospective and primary prevention studies are required, with detailed assessments of these risk factors and others such as silent myocardial ischaemia, postprandial lipids, retinopathy, fibrinogen, plasminogen activator inhibitor $\left(\mathrm{PAI}_{1}\right)$, autonomic neuropathy, and measures of left ventricular function, so that we can develop more accurate ways of predicting the risk of future coronary events and most importantly the benefits of risk factor reduction. It will also be important that these studies are performed in different populations and ethnic groups. 
With the present level of knowledge of risk assessment we have the means to identify a proportion of high risk patients who are very likely to benefit from intervention but in spite of this, many diabetes clinics fail to identify and manage them effectively. ${ }^{16}$

\section{Screening asymptomatic patients}

In the research setting and a limited number of clinical situations, ${ }^{17}{ }^{18}$ non-invasive testing has been used to establish a more precise estimate of the probability of coronary disease in asymptomatic patients. Standard cardiovascular risk factors yield the pretest probability of disease that is combined with the results of treadmill exercise testing, nuclear cardiography or stress echocardiography alone or in combination to establish the post-test probability of disease. This is sometimes sufficiently high to justify recommending coronary angiography with a view to identifying surgically treatable disease. ${ }^{19}$

There are several problems in applying this approach to screen all asymptomatic patients with or without diabetes. First, there is limited information regarding how well these tests influence the probability of future cardiac events. It is possible that only a small proportion of patients with positive non-invasive tests will experience subsequent cardiac events and many positive responders could experience the anxiety and insurance implications of being labelled at risk and possibly be subjected to further unnecessary, costly investigations with inherent risk. Second, there is little information regarding which, if any, high risk patients identified by these methods will benefit from treatment. Finally, there are financial and service implications.

Only asymptomatic insulin dependent patients with severe diabetic nephropathy have so far been shown to benefit from coronary disease screening with a view to coronary artery surgery before renal transplantation. ${ }^{19}$ Future research may identify additional groups who will benefit from intervention. One such group may be asymptomatic non-insulin dependent patients with microalbuminuria in whom we have recently found a strikingly high prevalence of silent myocardial ischaemia. ${ }^{8}$

Recent reports from the asymptomatic cardiac ischaemia pilot study have stimulated interest in screening asymptomatic subjects for coronary disease. Initial revascularisation appears to improve two year survival compared with anti-ischaemia treatment in patients with myocardial ischaemia and surgically treatable coronary disease..$^{20}$ However, only $17 \%$ of patients in this study had diabetes so larger studies are required before a good case can be made for surgical intervention in asymptomatic patients with diabetes.

Two important conditions would need to be satisfied before non-invasive testing could be recommended as a means of influencing medical treatment in asymptomatic patients with diabetes. First, the results of non-invasive testing would need to be shown to be independent predictors of coronary events ${ }^{21}$ and second, risk factor intervention would need to be shown to yield meaningful benefit. For example, with both conditions satisfied, a patient with a low or intermediate pretest probability of coronary disease, in whom aggressive medical treatment would not be indicated, a positive non-invasive test could increase the predicted probability of a coronary event sufficiently to justify lower target levels for lipids and blood pressure, and strengthen the case for statin, aspirin, $\beta$ blocker, and oestrogen replacement treatment. Risk factor intervention in non-diabetic men with evidence of silent myocardial ischaemia has been shown to improve survival ${ }^{22}$ and the identification of a positive test may motivate patients to be more compliant with risk factor modification. ${ }^{23}$

Patients with diabetes and coronary disease behave differently from non-diabetic patients. They have more aggressive coronary disease and experience worse outcomes at any stage of the disease process in spite of similar benefits from medical treatment. Further prospective and primary prevention studies are required to quantify cardiac risk more accurately, to determine the most appropriate risk thresholds for intervention, and to compare the efficacy of modern medical and surgical treatments. This is especially important for asymptomatic patients who, based on risk factors and non-invasive testing, are predicted to be at high risk of coronary death.

Senior Registrar

M K RUTTER

Diabetes Unit

Freeman Hospital

Newcastle upon Tyne, UK

Reader in Medicine and Consultant Physician

Royal Victoria Infirmary,
Newcastle upon Tyne, UK

S M MARSHALL

Consultant Cardiologist

Freeman Hospital,

Newcastle upon Tyne, UK

1 Currie CJ, Morgan C, Peters JR. Patterns and costs of diabetes and nondiabetes related coronary heart disease hospital care Heart 1997;78:544-9.

betes related coronary heart disease hospital care. Heart 1997;78:544-9. Framingham study. $\mathscr{F A M A}$ 1979;241:2035-8.

3 Stamler J, Vaccaro O, Neaton J, Wentworth D, for the MRFIT Research Group. Diabetes, other risk factors, and cardiovascular mortality for men screened in the multiple risk factor intervention trial. Diabetes Care 1993;16:434-44

4 Malmberg K, for the DIGAMI (Diabetes Mellitus Insulin Glucose Infusion in Acute Myocardial Infarction) Study Group. Prospective randomised study of intensive insulin treatment on long term survival after acute myocardial infarction in patients with diabetes mellitus. BMf 1997;314:151215 .

5 Herlitz J, Wognsen GB, Emanuelsson H, Haglid M, Karlson BW, Karlsson $\mathrm{T}$, et al. Mortality and morbidity in diabetic and non-diabetic patients during a 2-year period after coronary artery bypass grafting. Diabetes Care 1996;19:698-703.

6 The Bypass Angioplasty Revascularization Investigation (BARI) Investigators. Comparison of coronary bypass surgery with angioplasty in patients tors. Comparison of coronary bypass surgery with angiop
with multi-vessel disease. $N$ Engl $\mathcal{F}$ Med 1996;335:217-25.

7 Morris JJ, Smith LR, Jones RH. Influence of diabetes and mammary artery grafting on survival after coronary bypass. Circulation 1991;84(suppl 3):275-84

8 Rutter MK, McComb JM, Brady S, Marshall SM. Silent myocardial ischaemia, microalbuminuria and NIDDM [abstract]. Diabet Med 1996; 13(suppl 3):S52

9 Yudkin JS, Blauth C, Drury P, Fuller J, Henley J, Lancaster T, et al. Prevention and management of cardiovascular disease in patients with diabetes mellitus: an evidence base. Diabet Med 1996;13:S101-21.

10 Eastman RC, Keen H. The impact of cardiovascular disease on people with diabetes: the potential for prevention. Lancet 1997;350:SI29.

11 UK Prospective Diabetes Study Group. UK prospective diabetes study 16. Overview of 6 years' therapy of type II diabetes: a progressive disease. Diabetes 1995;44:1249-58.

12 Haq IU, Ramsay LE, Pickin DM, Yeo WW, Jackson PR, Payne JN. Lipid lowering for prevention of coronary heart disease: what policy now? Clin Sci 1996;91:399-413.

13 Shepherd J, Cobbe SM, Ford I, Isles CG, Lorimer AR, MacFarlane PW, et al. Prevention of coronary heart disease with pravastatin in men with hypercholesterolemia. West of Scotland Coronary Prevention Study Group. N Engl F Med 1995;333:1301-7.

14 ETDRS Investigators. Aspirin effects on mortality and morbidity in patients with diabetes mellitus. Early treatment diabetic retinopathy study report 14. FAMA 1992;268:1292-300

15 Anderson KM, Wilson PW, Odell PM, Kannel WB. An updated coronary risk profile. A statement for health professionals. Circulation 1991;83:356-62.

16 Rutter MK, Home PD, Alberti KGMM. Five-year follow-up of cardiovascular risk factors in people with newly diagnosed type 2 diabetes. Diab Nutr Metab 1996;9:299-305.

17 Manske CL, Thomas W, Wang Y, Wilson RF. Screening diabetic transplant candidates for coronary artery disease: identification of a low risk subgroup. Kidney Int 1993;44:617-21.

18 Camp AD, Garvin PJ, Hoff J, Marsh J, Byers SL, Chaitman BR. Prognostic value of intravenous dipyridamole thallium imaging in patients with value of intravenous dipyridamole thallium imaging in patients with
diabetes mellitus considered for renal transplantation. Am f Cardiol 1990; 65:1459-63.

19 Manske CL, Wang Y, Rector T, Wilson RF, White CW. Coronary revascularisation in insulin-dependent diabetic patients with chronic renal failure. Lancet 1992;340:998-1002.

20 Davies R, Goldberg A, Forman S, Pepine C, Knatterud G, Geller N, et al. Asymptomatic cardiac ischaemia pilot (ACIP) study two-year follow-up. Circulation 1997;95:2037-43.

21 Califf RM, Armstrong PW, Carver JR, D'Agostino RB, Strauss WE. 27th Bethesda conference: matching the intensity of risk factor management with the hazard for coronary disease events. Task Force 5. Stratification of patients into high, medium and low risk subgroups for purposes of risk factor management. F Am Coll Cardiol 1996;27:1007-19.

22 Multiple Risk Factor Intervention Trial Research Group. Exercise electrocardiogram and coronary heart disease mortality in the multiple risk factor intervention trial. Am 7 Cardiol 1985;55:16-24.

23 Bruce RA, DeRouen TA, Hossack KF. Pilot study examining the motivational effects of maximal exercise testing to modify risk factors and health habits. Cardiology 1980;66:111-19. 
STAMPS IN CARDIOLOGY

\section{The World Health Organisation}

The constitution of the World Health Organisation was signed on 22 July 1946 by representatives of 61 governments and came into force on 7 April 1948. This is commemorated as World Health Day and since 1962 many countries have issued stamps on this day to promote and advertise each year's different health theme. The first stamps appeared for the campaign "The world united against malaria". Other themes have included "Early detection of cancer saves lives" (1970) and

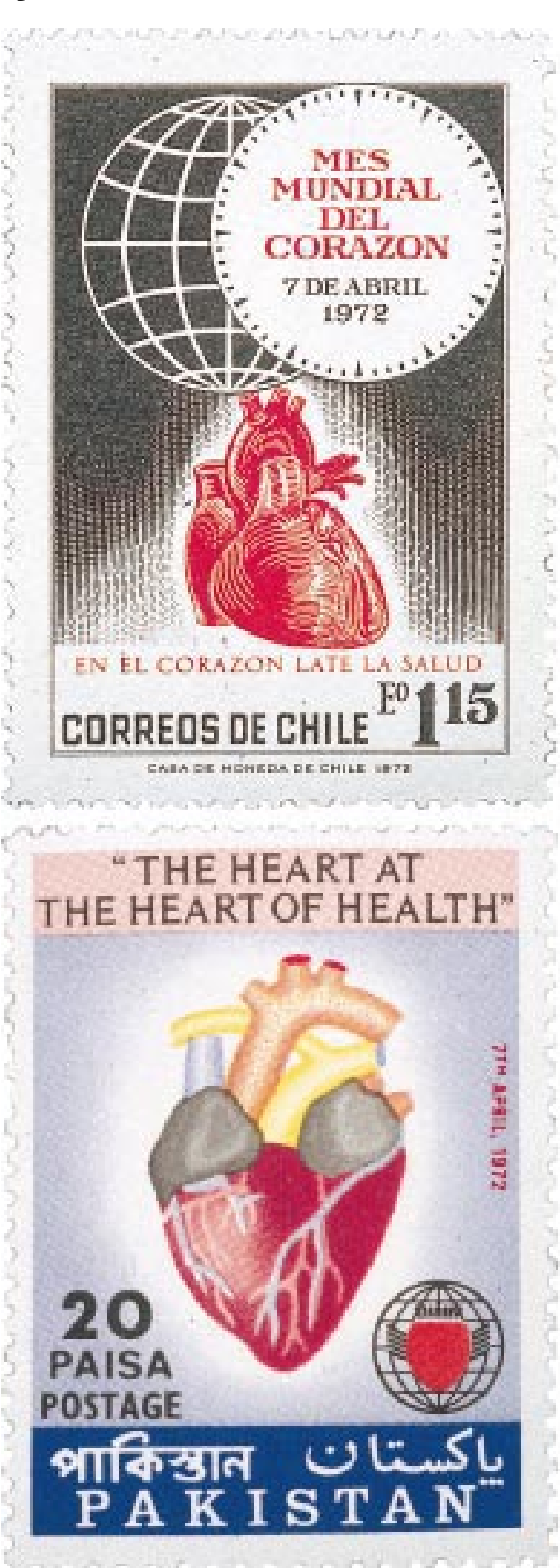

"The fight against drug abuse" (1976). In 1972 the World Health Day theme was "Your heart is your health" and a selection of philatelic designs appeared from countries across the world. The stamps from Chile and Pakistan bear the date of the World Health Day and the title of the 1972 campaign. The 50 franc stamp from Cameroon was issued in 1973 to commemorate the 25th anniversary of the World Health Organisation. The colours were carefully selected to depict the venous and arterial circulations with both halves of the stamp showing the heart and great vessels.

M K DAVIES A HOLLMAN

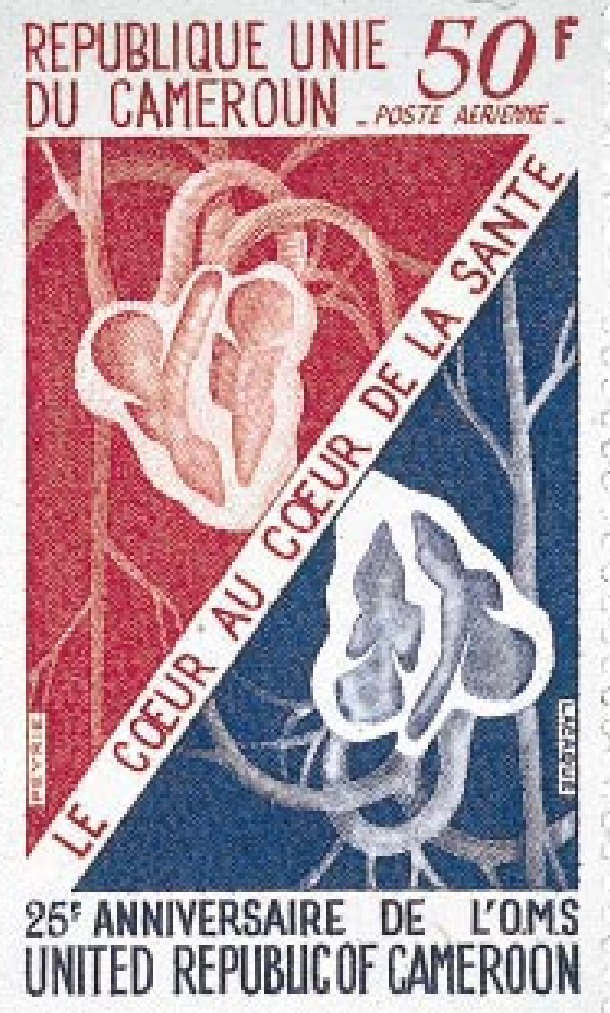

